\title{
Report of Psychological Competitive Ability of Rugby Players in Each Unit Who Belong to Companies
}

\author{
Takeru Hatachi, Koichiro Aoki, Chieko Kato \\ Graduate School of Information Sciences and Arts, Toyo University, Saitama, Japan \\ Email: hatachit@gmail.com
}

How to cite this paper: Hatachi, T., Aoki, K., \& Kato, C. (2019). Report of Psychological Competitive Ability of Rugby Players in Each Unit Who Belong to Companies. Psychology, 10, 1868-1879.

https://doi.org/10.4236/psych.2019.1013121

Received: August 26, 2019

Accepted: October 28, 2019

Published: October 31, 2019

Copyright (๑) 2019 by author(s) and Scientific Research Publishing Inc. This work is licensed under the Creative Commons Attribution International License (CC BY 4.0).

http://creativecommons.org/licenses/by/4.0/

\section{(c) (i) Open Access}

\begin{abstract}
The purpose of this study is to clear their psychological athletic ability by comparison between members and non-members as Team and Units, and also to assess the different of the psychological ability between elite rugby players and collegiate athletes and collect those data. This study conducted a survey on psychological-competitive ability of rugby players who belong to companies with a focus on members and non-members in a whole team included both Backs (BK) and Forwards (FW), or each unit. Comparison between these players and collegiate players was also carried out and their differences were clarified. The results of the survey showed that the members' scores of "Judgment" and "Strategic ability" were higher than the non-members' scores. The comparison with the collegiate players indicated that the elite players' scores of "Self-control", "Ability to relax", "Concentration", and "Mental stability and concentration" were higher than the collegiate players' score as well as the collegiate players' scores of "Volition for winning" and "Volition for competition" were higher than the elite players' scores. These results suggested that rugby players need decision making skills in the game situations and these psychological skills such as "Judgment" and "Strategic ability" are important in selection criteria of members and coaching guidelines even for the players who belong to companies.
\end{abstract}

\section{Keywords}

Psychological-Competitive Ability, Rugby Players, Psychological Tests

\section{Introduction}

\subsection{Research Back Ground}

Japan Top League was founded in 2003 and the environment around elite rugby 
players in Japan is, changing little by little. Since then, the physical and skill level of Japanese rugby has been getting better.

Japan rugby had only 1 win, and 2 draws in the World Cup History by 2015, but Japan national team beat Republic of South Africa in the 2015 World Cup and the media reported the win as "The miracle of Brighton". In this world cup, Japanese national team had three wins and one loses, but they could not advance to the tournament. But they are showing the improvement of Japanese rugby to both inside and outside of Japan. As mentioned previously, the level of Japanese rugby is getting higher. But the environments around elite rugby players in Japan are different, and depend on the team to which they belong. There are teams, which have mainly professional players, but also there are teams, which have some professional players and players who belong to companies. Especially, the teams which belong to the Top Challenge League tend to be a mixed one. In the environment around Japanese rugby now, it is very important for the team which has players who are working for the company to improve efficiently because of their limited training time. Improving psychological ability is very essential for their training. We need to think how we should coach and train the teams which have players working for the company to improve their ability to compete against the team whose players are mainly professional players.

\subsection{Purpose of This Study}

The purpose of this study is to clear their psychological athletic ability by comparison between members and non-members as Team and Units, and also to assess the difference of the psychological ability between elite rugby players and collegiate athletes and collect those data. Based on this assessment, making a plan to improve psychological ability for their future and linking this to how we coach athletes are important as well.

\subsection{Literature Review}

Not only rugby players but also other athletes need basic physical ability, skills, and specific physical ability and skills for each sport, which are required for them to perform better in the game with their own talent. Zushi (2014) showed that coaches and trainers can clear their goals and problems, choose their exercise or drills with limited time, and make a plan and execute them by understanding their goal of Sports performance very well and assess them properly. It is very important to do assessment from those aspects. Trainers and Coaches assess their ability by doing tests regularly in off-season, pre-season and in season, and having training matches. Based on the assessment, they plan to develop athletes' ability. It is clear recently that not just physical and skills ability but also psychological ability is very important to develop and execute those abilities.

Assessing psychological ability regularly is very important as much as assessing physical ability, or performance to improve athletes' ability systematically and efficiently. Takeno et al. (2014) studied the relationship between psychological competitive ability and athlete's performance in Soccer and Volleyball. They 
reported that a team with higher psychological competitive ability has better athletic performance in both sports. Therefore, assessing psychological competitive ability is very helpful to check their current athletic performance.

Researchers overseas used psychological ability assessment such as MTQ48 (Clough et al., 2002), and they pull out mental toughness and provide it as mental ability, which is seen in a controlled environment such as competitive sports (Nicholls et al., 2009).

Other psychological ability assessments for athletes were developed. One is, the Athletic Mindfulness, which was recently developed by Amemiya et al. (2015). Also other diagnostic inventory of psychological competitive ability for athletes such as DIPCA.3, was developed and improved by Tokunaga (2001). It consists of five factors and twelve lower scales and used to survey a lot of sports. Enda et al. used this test and surveyed collegiate athletes. They reported that athletes who were more talented showed higher psychological competitive ability.

There is some research, which used DIPCA.3 for surveying Rugby Football Team. The research by Terada et al. (1996) and Yonechi (2001) used high school athletes as their participants. There is the research by Okamoto et al. (1998) whose participants were collegiate athletes, and also Okamoto et al. (1996) used elite athletes for their participants. The number of women rugby players is increasing in the last decade. Tanuma \& Yonechi (2016) had a research, which compared men's players' psychological competitive ability with women players. Also, Yonechi \& Tanuma (2016) have a research about women's rugby players' year of careers as players, or as international players.

\section{Research Method}

\subsection{Participants}

The study involved 39 elite male rugby players, all belonging to teams in Japan Top Challenge League. The same 39 players were then divided for analyzing data for members and non-members. The study categorized players who played official games as "members (22 players, Mean age: $27.09 \pm 4.01$ )", and players who did not play official games as "non-members (17 players, Mean age: $25.23 \pm$ 2.70)".

Two groups were made to analyze data for each unit. One group was "FW (21 players, Mean age: $26.14 \pm 3.46$ )" which consists of Prop (PR), Hooker (HO), Lock (LO), Flanker (FL), and No 8. The other group was "BK (18 players, Mean age: $26.44 \pm 3.8$ )" which consists of Scrum Half (SH), Stand Off (SO), Center Three Backs (CTB), Wing Three Backs (WTB), and Full Backs (FB).

\subsection{Survey and Research Term}

Surveys were done in the 2018 season (Sep-Nov 2018). The team filled out the Ethical consent form before surveys were done. In addition, the elite rugby teams participated in this study as private organizations in order to get an outside evaluation of them, thus giving their players the opportunity to freely ex- 
press their views without having to consider coaches. Given these conditions, in accordance with Japanese rule on ethics, the material contained in the report can be used to compile an article.

Diagnostic inventory of psychological competitive ability for athletes (DIPCA.3) which was developed by Tokunaga was used. This research analyzed 12 lower scales as "Patience", "Aggressiveness", "Volition for self-realization", "Volition for winning", "Self-control”, "Ability to relax", "Concentration", "Confidence", "Decision", "Predictive ability", "Judgment", "Cooperation" and 5 factors as "Volition for competition", "Mental stability and concentration", "Confidence", and "Strategic ability" and total points.

If they had less than 12 points in Lie Scale, we planned to eliminate the data. But we could not find any data which was less than 12 points in Lie Scale.

We gave feedback of their individual results to all players to improve their ability.

\subsection{Statistics}

Each 12 lower scales and 5 factors of DIPCA.3 was used for analysis, and independent variables of the 2 groups were analyzed by T-test. The independent variables of more than 3 groups were analyzed by one-way analysis of variance. If significant variables were found, those variables were tested by Tukey. Statistical level was 5\%. IBM SPSS Ver. 25 was used for statistical analysis.

\section{Results}

\subsection{Unit: FW vs BK}

Independent Sample t-test was used to analyze the relationship of Psychological ability. Table 1 showed the relationship of Psychological ability as Units between Forward (FW) and Backs (BK).

As a Team, no significant differences were found in any factors and in lower scale between FW and BK.

\subsection{Unit: Members vs Non-Members}

Independent Sample t-test was used to analyze the relationship of psychological ability between "members" and "non-members" in a team. Table 2 showed the analysis of 2 groups in a team such as "members" and "non-members". It showed "members" were significantly higher than "non-members" in "Judgment ( $p$ $<.05)$ " and "Strategic ability $(p<.05)$ ".

Independent Sample t-test was used to analyze the relationship of psychological ability between "members" and "non-members" in each unit. Table 3 and Table 4 showed the analysis of 2 groups in each unit such as "members" and "non-members". It showed that "FW (members)" was significantly higher than "FW (non-members)" in "Predictive ability $(p<.05)$ ", "Judgment $(p<.001)$ ", and "Strategic ability $(p<.001)$ ". No significant differences were found in any other factors and lower scale. 
Table 1. Comparison of 12 lower scales and 5 factors between FW and BK.

\begin{tabular}{|c|c|c|c|c|c|}
\hline \multirow{2}{*}{12 lower scales } & \multicolumn{2}{|c|}{ FW } & \multicolumn{2}{|c|}{ BK } & \multirow{2}{*}{$\mathrm{t}$-value } \\
\hline & M & SD & M & $\mathrm{SD}$ & \\
\hline 1) Patience & 15.14 & 3.40 & 14.61 & 2.55 & 0.55 \\
\hline 2) Aggressiveness & 16.43 & 2.73 & 14.50 & 4.09 & 1.70 \\
\hline 3) Volition for self-realization & 14.90 & 2.84 & 15.78 & 3.17 & -0.91 \\
\hline 4) Volition for winning & 14.00 & 2.61 & 13.50 & 2.83 & 0.57 \\
\hline 5) Self-control & 15.90 & 3.60 & 15.56 & 3.07 & 0.32 \\
\hline 6) Ability to relax & 15.00 & 3.89 & 14.72 & 3.89 & 0.22 \\
\hline 7) Concentration & 16.14 & 3.41 & 16.28 & 3.21 & -0.13 \\
\hline 8) Confidence & 12.76 & 3.03 & 13.00 & 3.09 & -0.24 \\
\hline 9) Decision & 12.76 & 2.59 & 13.67 & 1.97 & -1.21 \\
\hline 10) Predictive ability & 12.05 & 2.29 & 13.28 & 2.35 & -1.65 \\
\hline 11) Judgement & 12.29 & 3.29 & 13.22 & 2.94 & -0.93 \\
\hline 12) Cooperation & 16.05 & 2.29 & 16.83 & 2.41 & -1.04 \\
\hline \multicolumn{6}{|l|}{5 factors } \\
\hline Volition for competition & 60.48 & 8.35 & 58.39 & 9.06 & 0.75 \\
\hline Mental stability and concentration & 47.05 & 10.37 & 46.56 & 8.30 & 0.16 \\
\hline Confidence & 25.52 & 5.33 & 26.67 & 4.49 & -0.72 \\
\hline Strategic ability & 24.33 & 5.20 & 26.50 & 4.09 & -1.43 \\
\hline Cooperation & 16.05 & 2.29 & 16.83 & 2.41 & -1.04 \\
\hline Total points & 173.43 & 19.36 & 174.94 & 18.26 & -0.25 \\
\hline
\end{tabular}

Table 2. Comparison of 12 lower scales and 5 factors between members and non-members.

\begin{tabular}{|c|c|c|c|c|c|}
\hline \multirow{2}{*}{12 lower scales } & \multicolumn{2}{|c|}{ Members } & \multicolumn{2}{|c|}{ Non-members } & \multirow{2}{*}{ t-value } \\
\hline & M & SD & M & $\mathrm{SD}$ & \\
\hline 1) Patience & 15.45 & 3.23 & 14.18 & 2.60 & 1.33 \\
\hline 2) Aggressiveness & 15.68 & 3.48 & 15.35 & 3.66 & 0.29 \\
\hline 3) Volition for self-realization & 14.86 & 2.90 & 15.88 & 3.10 & -1.06 \\
\hline 4) Volition for winning & 13.91 & 2.49 & 13.59 & 3.00 & 0.37 \\
\hline 5) Self-control & 16.32 & 3.03 & 15.00 & 3.64 & 1.23 \\
\hline 6) Ability to relax & 14.86 & 3.34 & 14.88 & 4.51 & -0.02 \\
\hline 7) Concentration & 16.77 & 2.64 & 15.47 & 3.92 & -0.01 \\
\hline 8) Confidence & 13.18 & 3.00 & 12.47 & 3.09 & 1.18 \\
\hline 9) Decision & 13.41 & 2.32 & 12.88 & 2.40 & 0.73 \\
\hline 10) Predictive ability & 12.95 & 2.28 & 12.18 & 2.48 & 1.33 \\
\hline 11) Judgement & 13.91 & 2.52 & 11.18 & 3.23 & $0.29^{*}$ \\
\hline 12) Cooperation & 16.68 & 2.40 & 16.06 & 2.30 & -1.06 \\
\hline \multicolumn{6}{|l|}{5 factors } \\
\hline Volition for competition & 59.91 & 8.54 & 59.00 & 8.99 & 0.32 \\
\hline Mental stability and concentration & 47.95 & 7.72 & 45.35 & 11.20 & 0.86 \\
\hline Confidence & 26.59 & 4.67 & 25.35 & 5.30 & 0.77 \\
\hline Strategic ability & 26.86 & 4.06 & 23.35 & 5.04 & $2.41^{*}$ \\
\hline Cooperation & 16.68 & 2.40 & 16.06 & 2.30 & 0.82 \\
\hline Total points & 178.00 & 15.58 & 169.12 & 21.40 & 1.50 \\
\hline
\end{tabular}

$*: p<.05$. 
Table 3. Comparison of 12 lower scales and 5 factors between FW (members) and FW (non-members).

\begin{tabular}{|c|c|c|c|c|c|}
\hline \multirow{2}{*}{12 lower scales } & \multicolumn{2}{|c|}{ FW (members) } & \multicolumn{2}{|c|}{ FW (non-members) } & \multirow{2}{*}{ t-value } \\
\hline & M & SD & $\mathrm{M}$ & $\mathrm{SD}$ & \\
\hline 1) Patience & 15.58 & 3.61 & 14.56 & 3.21 & 0.68 \\
\hline 2) Aggressiveness & 16.08 & 3.03 & 16.89 & 2.37 & -0.66 \\
\hline 3) Volition for self-realization & 14.50 & 2.94 & 15.44 & 2.79 & -0.75 \\
\hline 4) Volition for winning & 13.33 & 2.54 & 14.89 & 2.57 & -1.38 \\
\hline 5) Self-control & 16.92 & 3.06 & 14.56 & 4.00 & 1.54 \\
\hline 6) Ability to relax & 16.08 & 2.64 & 13.56 & 4.90 & 1.40 \\
\hline 7) Concentration & 17.08 & 2.47 & 14.89 & 4.20 & 1.40 \\
\hline 8) Confidence & 13.50 & 2.68 & 11.78 & 3.35 & 1.31 \\
\hline 9) Decision & 13.58 & 2.43 & 11.67 & 2.50 & 1.77 \\
\hline 10) Predictive ability & 13.08 & 1.88 & 10.67 & 2.12 & $2.76^{*}$ \\
\hline 11) Judgement & 14.17 & 2.52 & 9.78 & 2.44 & $4.01^{* *}$ \\
\hline 12) Cooperation & 16.33 & 2.67 & 15.67 & 1.73 & 0.65 \\
\hline \multicolumn{6}{|l|}{5 factors } \\
\hline Volition for competition & 59.50 & 8.38 & 61.78 & 8.63 & -0.61 \\
\hline Mental stability and concentration & 50.08 & 7.34 & 43.00 & 12.74 & 1.49 \\
\hline Confidence & 27.08 & 4.74 & 23.44 & 5.62 & 3.87 \\
\hline Strategic ability & 27.25 & 3.77 & 20.44 & 4.28 & $0.65^{* *}$ \\
\hline Cooperation & 16.33 & 2.67 & 15.67 & 1.73 & 2.00 \\
\hline Total points & 180.25 & 14.99 & 164.33 & 21.57 & -0.61 \\
\hline
\end{tabular}

${ }^{* *}: p<.01, *: p<.05$.

Table 4. Comparison of 12 lower scales and 5 factors between BK (members) and BK (non-members).

\begin{tabular}{|c|c|c|c|c|c|}
\hline \multirow{2}{*}{12 lower scales } & \multicolumn{2}{|c|}{ BK (members) } & \multicolumn{2}{|c|}{ BK (non-members) } & \multirow{2}{*}{ t-value } \\
\hline & M & $\mathrm{SD}$ & M & SD & \\
\hline 1) Patience & 15.00 & 2.92 & 14.22 & 2.22 & 0.64 \\
\hline 2) Aggressiveness & 14.78 & 4.09 & 14.22 & 4.32 & 0.28 \\
\hline 3) Volition for self-realization & 15.22 & 3.11 & 16.33 & 3.32 & -0.73 \\
\hline 4) Volition for winning & 14.56 & 2.51 & 12.44 & 2.88 & 1.66 \\
\hline 5) Self-control & 16.00 & 2.87 & 15.11 & 3.37 & 0.60 \\
\hline 6) Ability to relax & 13.33 & 3.84 & 16.11 & 3.62 & -1.58 \\
\hline 7) Concentration & 16.67 & 2.96 & 15.89 & 3.59 & 0.50 \\
\hline 8) Confidence & 13.00 & 3.61 & 13.00 & 2.69 & 0.00 \\
\hline 9) Decision & 13.67 & 1.87 & 13.67 & 2.18 & 0.00 \\
\hline 10) Predictive ability & 13.11 & 2.76 & 13.44 & 2.01 & -0.29 \\
\hline 11) Judgement & 14.11 & 2.21 & 12.33 & 3.43 & 1.31 \\
\hline 12) Cooperation & 17.22 & 2.17 & 16.44 & 2.70 & 0.67 \\
\hline \multicolumn{6}{|l|}{5 factors } \\
\hline Volition for competition & 59.56 & 9.28 & 57.22 & 9.23 & 0.54 \\
\hline Mental stability and concentration & 46.00 & 7.95 & 47.11 & 9.08 & -0.28 \\
\hline Confidence & 26.67 & 4.53 & 26.67 & 4.72 & 0.00 \\
\hline Strategic ability & 27.22 & 3.96 & 25.78 & 4.32 & 0.74 \\
\hline Cooperation & 17.22 & 2.17 & 16.44 & 2.70 & 0.67 \\
\hline Total points & 176.67 & 17.05 & 173.22 & 20.27 & 0.39 \\
\hline
\end{tabular}


Also, no significant differences were found in any factors and lower scale between "BK (members)" and "BK (non-members)".

One-way analysis of variance was used to analyze the relationship of psychological ability among 4 groups. Table 5 showed comparison of 4 groups such as "FW (members)", "FW (non-members)", "BK (members)" and "BK (non-members)". It showed that "FW (members)" and "BK (members)" had significantly higher scores than "FW (Non-members)" in "Judgment $(p<.05)$ " and "Strategic ability $(p<.05)$ ".

\subsection{Comparison with Collegiate Players}

Table 6 showed the comparison by using One Sample t-test between the results of this research ("elite players") and the study by Tanuma \& Yonechi (2016) which targeted collegiate rugby players' psychological abilities.

About 5 factors, elite players had significantly higher scores than collegiate players in "Confidence $(p<.05)$ ", "Mental stability and concentration $(p<.01)$ ". On the other hand, collegiate players were significantly higher than elite players in "Volition for competition $(p<.05)$ ".

Table 5. Comparison of 12 lower scales and 5 factors between 4 groups.

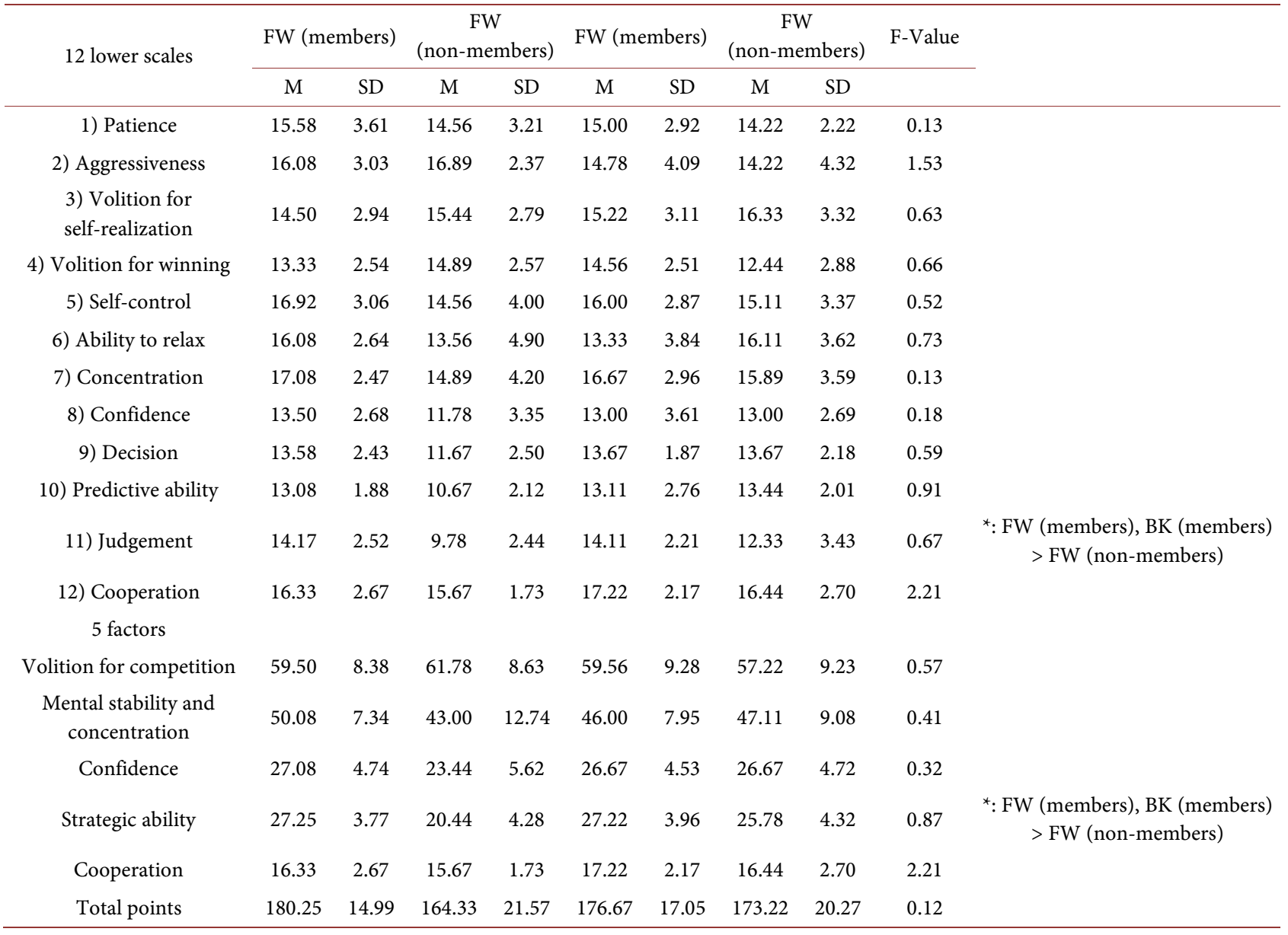

${ }^{* *}: p<.01,{ }^{*}: p<.05$. 
Table 6. Comparison of 12 lower scales and 5 factors between 4 groups.

\begin{tabular}{|c|c|c|c|c|}
\hline \multirow{2}{*}{12 lower scales } & \multicolumn{2}{|c|}{ Elite players } & \multirow{2}{*}{$\begin{array}{c}\text { Collegiate players } \\
\mathrm{M}\end{array}$} & \multirow{2}{*}{ t-value } \\
\hline & M & $\mathrm{SD}$ & & \\
\hline 1) Patience & 14.90 & 3.01 & 14.61 & 0.60 \\
\hline 2) Aggressiveness & 15.54 & 3.52 & 16.29 & -1.34 \\
\hline 3) Volition for self-realization & 15.31 & 2.99 & 16.26 & -1.99 \\
\hline 4) Volition for winning & 13.77 & 2.69 & 15.93 & $-5.02^{\star *}$ \\
\hline 5) Self-control & 15.74 & 3.33 & 13.93 & $3.40^{* *}$ \\
\hline 6) Ability to relax & 14.87 & 3.84 & 12.47 & $3.91^{* *}$ \\
\hline 7) Concentration & 16.21 & 3.28 & 14.47 & $3.31^{* *}$ \\
\hline 8) Confidence & 12.87 & 3.02 & 11.86 & $2.09^{*}$ \\
\hline 9) Decision & 13.18 & 2.34 & 12.22 & $2.56^{*}$ \\
\hline 10) Predictive ability & 12.62 & 2.37 & 12.29 & 0.86 \\
\hline 11) Judgement & 12.72 & 3.13 & 11.92 & 1.59 \\
\hline 12) Cooperation & 16.41 & 2.35 & 16.38 & 0.08 \\
\hline \multicolumn{5}{|l|}{5 factors } \\
\hline Volition for competition & 59.51 & 8.63 & 63.10 & $-2.60^{*}$ \\
\hline Mental stability and concentration & 46.82 & 9.35 & 40.88 & $3.97^{* *}$ \\
\hline Confidence & 26.05 & 4.93 & 24.08 & $2.50^{*}$ \\
\hline Strategic ability & 25.33 & 4.79 & 24.21 & 1.47 \\
\hline Cooperation & 16.41 & 2.35 & 16.38 & 0.08 \\
\hline Total points & 174.13 & 18.63 & 168.64 & 1.84 \\
\hline
\end{tabular}

${ }^{* *}: p<.01, *: p<.05$.

About 12 lower scales, elite players were significantly higher than collegiate players in "Confidence $(p<.05)$ ", "Decision $(p<.05)$ ", "Self-control $(p<.01)$ ", "Ability to relax $(p<.01)$ ", and "Concentration $(p<.01)$ ". On the other hand, collegiate players were significantly higher than elite players in "Volition for winning $(p<.01)$ ".

\section{Discussion}

\subsection{Unit}

There is no significant difference between FW and BK on the team in 5 factors and 12 lower scales. This result showed a contrast from research by Okamoto et al. (1996) which said that BK was significantly higher than FW in "Decision" and "Strategic ability". We might be able to say that there is no difference between FW and BK in this team in "Decision" and "Strategic ability".

On the other hand, when we made a comparison between members and non-members, members had a significantly higher score than non-members in "Decision" and "Strategic ability". These results showed that understanding rugby and details of tactics were essential factors when coaches selected players for the games in this team. 
When we looked at the results between members and non-members in FW, it showed that members had a significant higher score in "Predictive ability" and "Judgment" in 12 lower factors, and "Strategic ability" in 5 Factors. These results showed that coaches looking at their "Predictive ability" and "Judgment" which come from understanding rugby and details of tactics, and "Strategic ability" which is a factor of these scales when they selected members for a game on this team.

On the other hand, there is no significant difference between members and non-members in BK. This result showed that the standard of member selection for BK is different from FW. Coaches were looking at their "Predictive ability", "Judgment" and "Strategic ability" for FW member selection, but the BK coach was looking at other factors as a standard of member selection for BK.

Research by Okamoto showed that BK is significantly higher than FW in "Predictive ability", "Judgment" and "Strategic ability". These showed that BK has training to improve those abilities in regular training, or that players who have aptitude for those abilities are playing rugby as BK.

When we compared 4 groups of "FW (members)", "FW (non-members)", "BK (members)", and "BK (non-members)", "FW (members)" and "BK (members)" had higher scores than "FW (non-members)" in "Judgment" and "Strategic ability". As mentioned previously about differences in teams and between members and non-members in a unit, non-members in FW, had less understanding of tactics and strategies in this team. Coaching understanding of tactics and strategies to non-members in FW is very important to improve the whole team.

\subsection{Comparison between Elite Players and Collegiate Players}

About 5 factors, elite players had significantly higher scores than collegiate players in "Confidence" and "Mental stability and concentration". On the other hand, collegiate players had significantly higher scores than elite players in "Volition for competition".

About the 12 lower scales, elite players had significantly higher scores than collegiate players in "Confidence", "Self-control", "Ability to relax", "Concentration", and "Decision". On the other hand, collegiate players had significantly higher scores than elite players in "Volition for winning". Also, collegiate players had a higher tendency than elite players in "Volition for self-realization".

Elite players had higher scores than collegiate players in "Mental stability and concentration" and lower scale of factors such as "Confidence", "Self-control", and "Ability to relax", and "Concentration". These results were matched with not only the study by Takizawa et al. (2018), which reported that experienced players had higher scores in "Self-control" and "Mental stability and concentration", but also Study by Takenouchi \& Oohata (2015), which reported accomplishment of psychological development task are related to psychological ability very much. Even this study showed that experience and accomplishment of psychological development task are related to psychological ability very much. 
On the other hand, elite players had significantly lower score than collegiate players in "Volition for competition" in 5 factors. Also, they had a significantly lower score than collegiate players in "Volition for winning" which is the lower scale of "Volition for competition", and they have lower tendency in "Volition for self-realization". These results are same as Takizawa et al.'s study (2018), which reported that less experienced player had significantly higher score in "Volition for self-realization". Elite players have more opportunity to think about reality based on their life experience because they were matured as a person and they were working in society. Because of it, they are losing of challenging to their own potential, self -affirmation to win as players, and motivation to their future. We assume these are the reason elite athlete had lower score than collegiate player in "Volition for competition", "Volition for winning", and "Volition for self-realization".

The study of Kashizuka et al. (2000), whose participants were handball player, and the study of Tanuma \& Yonechi (2016) whose participants were rugby players reported that experienced players were getting their "Judgment" and "Strategic ability" higher. However, experienced players in this study did not have higher scores related to "Strategic ability" than collegiate players. We have to coach this aspect which did not match to previous studies, to improve ability to compete as one of team tasks in the future.

\subsection{Summary of findings}

Summary of results in this study were the followings:

1) "Judgment" and "Strategic ability" of members of teams and FW were higher than non-members. In addition, "Predictive ability" of FW members was also higher than FW non-members. Also, members of FW and BK had higher "Judgment" and "Strategic ability" than non-members of FW.

2) Elite rugby players had higher "Self-control", and "Ability to relax", "Concentration" and "Mental stability and concentration" than collegiate players. However, collegiate players had higher "Volition for winning" and "Volition for competition" than elite rugby players.

\section{Conclusion}

The purpose of this study was to clear their psychological athletic ability by comparison between members and non-members as a team and unit, and also to assess the difference of the psychological ability between elite rugby players and collegiate athletes and collect those data. Based on them, making plans to improve psychological ability for their future and linking how we coach the athletes as well.

Participants in this study were 39 players who belong to elite rugby team and Diagnostic inventory of psychological competitive ability for athletes (DIPCA.3) was used. The results of this study showed the followings:

1) In comparison between members and non-members of elite rugby players, 
"Judgment" and "Strategic ability" of members were higher than non-members. In comparison between members and non-members of FW, "Predictive ability", "Judgment" and "Strategic ability" of members were higher than non-members. Also, members of FW and BK had higher "Judgment" and "Strategic ability" than non-members of FW.

2) In comparison between elite rugby players and collegiate rugby players, elite rugby players had higher "Self-control", "Ability to relax", "Concentration" and "Mental stability and concentration" than collegiate players. However, collegiate players had higher "Volition for winning" and "Volition for competition" than elite rugby players.

From these results, we concluded that that rugby players need decision making skills in game situations, and psychological skills such as "Judgment" and "Strategic ability" are important in selection criteria of members and coaching guidelines even for the players who belong to companies.

As the previous study of Yonechi et al. (1997) showed that decision making skills in situations are very important, we confirmed that this skill is very important even for elite rugby players when they were selected as members and when coach made a coaching guideline for their team. Also, we confirmed about the relationship between accomplishment of psychological development tasks and improvement of psychological competitive ability like Takizawa et al. showed previously. Based on these results, it will be very helpful as guidelines for coaching rugby and its development of psychological competitive ability. We think that this will link to efficient team development to coach by assessing team characteristics. In this study, we picked up participants from one team and used one psychological assessment. Therefore, we may need to study by using other teams and other psychological assessments to know a tendency in the future.

\section{Conflicts of Interest}

The authors declare no conflicts of interest regarding the publication of this paper.

\section{References}

Amemiya, R., Yusa, Y., \& Sakairi, Y. (2015). Development of a Mindfulness Questionnaire for Athletes. Japanese Journal of Cognitive Therapy, 8, 106-115.

Clough, P. J., Earle, K., \& Sewell, D. (2002). Mental Toughness: The Concept and Its Measurement. In I. Cockerill (Ed.), Solutions in Sport Psychology (pp. 32-45). London: Thomson.

Kashizuka, S., Date, M., Tajima, Y., \& Tanaka, M. (2000). A Study on the Psychological-Competitive Ability of the Woman Handball Players: Comparison by the Experience as Players and the Event Participation Experience. The Bulletin of Mukogawa Women's University. Humanities and Social Science, 48, 55-62.

Nicholls, A. R., Polman, R. C. J., Levy, A. R., \& Backhouse, S. H. (2009). Mental Toughness in Sport: Achievement Level, Gender, Age, Experience, and Sport Type Differences. Personality and Individual Differences, 47, 73-75.

https://doi.org/10.1016/j.paid.2009.02.006 
Okamoto, M., Takatsu, H., \& Terada, Y. (1998). A Research of Trait Phychological-Competitive Ability for College Rugby Players: About Experience, Balance and Beginning Time. Bulletin of Aichi Institute of Technology. Part A, 33, 85-88.

Okamoto, M., Takatsu, H., Takada, M., \& Terada, Y. (1996). A Research of Trait Phychological-Competitive Ability for Senior Rugby Players: Its Effect on the Performance and Comparison of the Two Positions. Bulletin of Aichi Institute of Technology. Part A, 31, 23-26.

Takeno, Y., Okano, K, Iju, A., \& Kinjo, K. (2014). An Early Study of Relationship between Psychological Competitive Ability and Athletes' Performance in Volleyball and Soccer. Bulletin of Joetsu University of Education, 33, 259-268.

Takenouchi, T., \& Oohata, M. (2015). Achievement of Psychosocial Developmental Tasks and Psychological Competitive Ability of Junior High School Athletes. Nagoya Journal of Health, Physical Fitness \& Sports, 38, 13-19.

Takizawa, H., Muramoto, M., Kurita, Y., Sasakawa, K., \& Takane, S. (2018). On Psychological Competitive Ability of Ultimate Players (The Fourth Report). Bulletin of Faculty of Business Administration Tokoha University, 5, 51-61.

Tanuma, H., \& Yonechi, T. (2016). Comparison of Male and Female Rugby Football Players on Psychological Competitive Ability. Journal of Physical Exercise and Sports Science, 22, 47-52.

Terada, Y., Okamoto, M., \& Takatsu, H. (1996). A Study on Psychological Competitive Ability of High School Rugby Football Players. The Journal of Science of Culture and Humanities, 57, 39-44.

Tokunaga, M. (2001). Evaluation Scales for Athletes' Psychological Competitive Ability: Development and Systematization of the Scales. Journal of Health Science, 23, 91-102.

Yonechi, T. (2001). Examination on Psyshological Competitive Ability of Rugby Football Players: The Case of High School National Team Players. Hagi International University Review, 3, 1-10.

Yonechi, T., \& Tanuma, H. (2016). A Study on the Psychological-Competitive Ability of the Female Rugby Football Players: Focusing on Experience of National Team Participation and Careers. Journal of Physical Exercise and Sports Science, 22, 47-52.

Yonechi, T., Tomita, H., Muranaka, H., Shibata, K., \& Osada, K. (1997). A Study on Decision Making for the Rugby Football Players: Situational Cognition Ability for the Defensive Players. Bulletin of Nippon Sport Science University, 26, 231-236.

Zushi, K. (2014). A Coaching Model and General Coaching Contents Required in Physical Education. The Japan Journal of Coaching Studies, 27, 149-161. 